\title{
TREATMENT OF BENIGN PROSTATIC HYPERPLASIA BY TRANSURETHRAL ULTRASOUND-GUIDED LASER-INDUCED PROSTATECTOMY (TULIP): EFFECTS ON URODYNAMIC PARAMETERS AND SYMPTOMS
}

\author{
J.L.H. RUUD BOSCH, M.D. \\ JAN GROEN, M.D. \\ FRITZ H. SCHRÖDER, M.D., PH.D.
}

From the Department of Urology, Erasmus University and Academic Hospital, Rotterdam, The Netherlands

\begin{abstract}
Objectives. This prospective study was undertaken to evaluate the effects of transurethral ultrasound-guided laser-induced prostatectomy (TULIP) on urodynamic, symptomatic, and prostate volume parameters as well as serum prostate-specific antigen.

Methods. The TULIP procedure was performed in 33 patients with benign prostatic hyperplasia with a mean age of 66 years. Patients were evaluated by pressure-flow studies, prostate volume measurement by transrectal ultrasound, and the American Urological Association (AUA) symptom score.

Results. At 3-month follow-up, laser prostatectomy has resulted in an increased maximum flow rate from $6.6 \pm 0.5$ to $11.2 \pm 0.6 \mathrm{~mL} / \mathrm{s}$ and in an objectively proven relief of the urodynamic obstruction, as is evident by a decrease of the average value of the urethral resistance parameter URA and the detrusor pressure at maximum flow rate from $38.3 \pm 2.7$ to $21.3 \pm 1.3 \mathrm{~cm}$ water and from $62.7 \pm 4$ to $38.9 \pm 2.1 \mathrm{~cm}$ water, respectively. Symptomatic improvement is evident from a decrease in the AUA symptom score from 20.4 at baseline to 8.8 at 6 -month follow-up. Although the total symptom score did not change significantly between 6 months and 1 year follow-up, the score of the symptom "weak stream" was significantly higher again at 12 months follow-up.

Conclusions. The TULIP procedure is a urodynamically and symptomatically effective treatment. Conclusions about the durability of this treatment modality should be made with reservations.
\end{abstract}

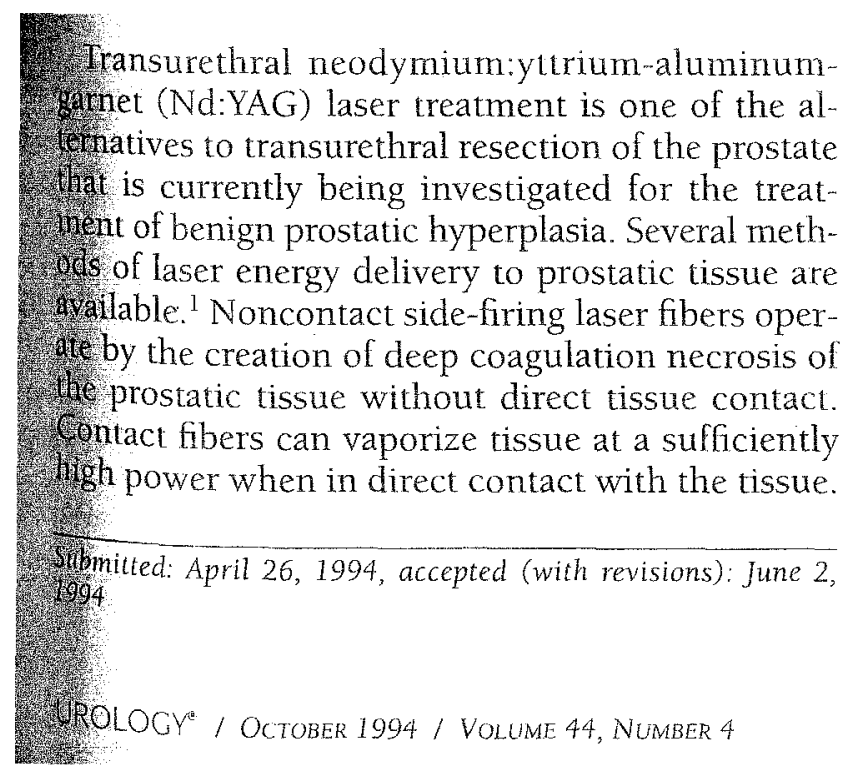

Although most side-firing fibers are operated under direct vision, transurethral ultrasound-guided laser-induced prostatectomy (TULIP) is a technology that utilizes the side-firing principle under ultrasound guidance. Via the transurethral route, the prostate is irradiated in a systematic way by a Nd:YAG laser source.

This study was initiated to determine objectively the effects of this treatment modality on urody. namic (urethral resistance) parameters, symptom score, prostate volume, and serum prostate-specific antigen (PSA).

Data on symptomatic changes and changes in uroflowmetry values have been reported previously 
for the TULIP procedure ${ }^{2}$ and for visual laser ablation of the prostate (VLAP) ${ }^{3,4}$ This study addresses changes in urethral resistance parameters after laser treatment for benign prostatic hyperplasia.

\section{MATERIAL AND METHODS}

\section{PROCEDURE}

The TULIP system consists of an ultrasound imager and a $20 \mathrm{~F}$ transurethral probe that incorporates a side-firing laser window positioned between two halves of a split ultrasound transducer. The TULIP probe is enclosed in a sleeve that incorporates a balloon at its distal end. The balloon, which is filled and pressurized with sterile water, creates a constant standoff from the tissue, stabilizes the system in the prostatic urethra, and decreases blood flow in the tissue. The 2 atmospheres of balloon pressurization are not associated with a dilation effect. ${ }^{5}$ The part of the probe that contains the laser window and the ultrasound transducer can be moved in a longitudinal and rotational fashion in the working window, which is created by the pressurized balloon. The TULIP system was coupled to a $60 \mathrm{~W}$ Nd:YAG laser set at $40 \mathrm{~W}$. The procedure has been described in detail by McCullough et al. ${ }^{2}$ In the present series $48 \mathrm{~F}$ balloons were used in all but 2 patients. Laser passes were initiated with a 5second dwelling time at the bladder neck followed by a pull rate of $1 \mathrm{~mm} / \mathrm{s}$. Laser passes were terminated when the thickness of the prostatic tissue became $1 \mathrm{~cm}$ on the ultrasound imager. An average of 8 to 10 passes in different positions were made per patient. After the procedure, cystoscopy was performed to check for blanching of the prostatic urethra, and a suprapubic catheter was inserted.

\section{STUDY PARAMETERS}

Prostate volume was measured by transrectal ultrasound with a $7 \mathrm{MHz}$ Bruel and Kjaer multiplane sector scanning probe. The planimetric technique of volume measurement was used at baseline and 3 months post-treatment. ${ }^{6}$ Serum PSA levels (Hybritech-Tandem) were measured at baseline and 24 and 48 hours, 1 week, and 3 months postoperatively. Prostate biopsies were performed in all men with PSA more than $10 \mathrm{ng} / \mathrm{mL}$ and in all men who had hypoechogenic lesions on transrectal ultrasound. No prostate cancers were detected in the men included in this study.

The American Urological Association (AUA) symptom index was determined at baseline and 3, 6 , and 12 months post-treatment. ${ }^{7}$

The postvoid residual urine volume (in milli liters) was measured by transabdominal ultrasound using an Aloka machine with a $3.5 \mathrm{MHz}$ handheld probe using the formula: $\pi / 6 \times($ width $) \times$ (height $\times$ (depth) ${ }^{8}$ Measurements were done at baseline? and 3,6 , and 12 months post-treatment.

Flow rates at 6 and 12 months are not reportes because most patients did not produce voided vot umes in excess of $100 \mathrm{~mL}$, whereas voided vol umes varied widely on different occasions, which would make comparisons not very relevant. Only the flow rates obtained during the controlled situ ation of the urodynamic tests at baseline and at 3 months follow-up are considered.

At baseline and 3 months post-treatment, urody namic studies, including pressure-flow studies were done: the parameters URA (a group-specifi urethral resistance factor), ${ }^{9} \mathrm{P}_{\text {det.Qmax }}, \mathrm{Q}_{\max }$, ano $\mathrm{W}_{\max }^{10}$ (a bladder contractility parameter) were de termined. The values for $\mathrm{P}_{\text {det.Qmax }}$ were plotted the Abrams-Griffiths nomogram. ${ }^{1.1}$

The protocol allows for repeat urodynamic stude ies after the 3-month period if during further fol low-up the symptom index showed a significani deterioration (increase of 7 or more points, ie, average increase of at least 1 point per symptom) together with an increase or stabilization of the residual urine volume above $50 \mathrm{~mL}$.

\section{PATIENTS}

The 33 patients had an average age of 66 years (range, 50 to 79 years). The average prostate vol: ume was $56 \mathrm{~cm}^{3}$ (range, 20 to $118 \mathrm{~cm}^{3}$ ). The ay erage preoperative symptom score as measured 6 ) the AUA-7 index was 21.3 (range, 5 to 35). Th patients were in retention before the treatment All patients had a 5-day course of prophylactic a tibiotics. A minimum follow-up of 3 months available in all patients. Twenty-six and $17 \mathrm{P}$ tients were followed for 6 and 12 months, respet tively.

\section{STATISTICAL ANALYSIS}

Wilcoxon's matched pairs signed rank test wit used to determine the significance of differences between two series of measurements of a particul parameter at two different times. The level of sit nificance was set at $\mathrm{p}<0.05$.

\section{RESULTS}

The average amount of energy ( \pm SE) delive to the prostate was $13,272 \pm 936 \mathrm{~J}$.

Patients were discharged after an average of 3 days (range, 2 to 10 ). The first micturition per dir thra occurred after an average of 2.7 days (range) to 29). The suprapubic catheter was removed afie an average of 19 days (range, 1 to 139) when th residual urine was less than one third of the mith 

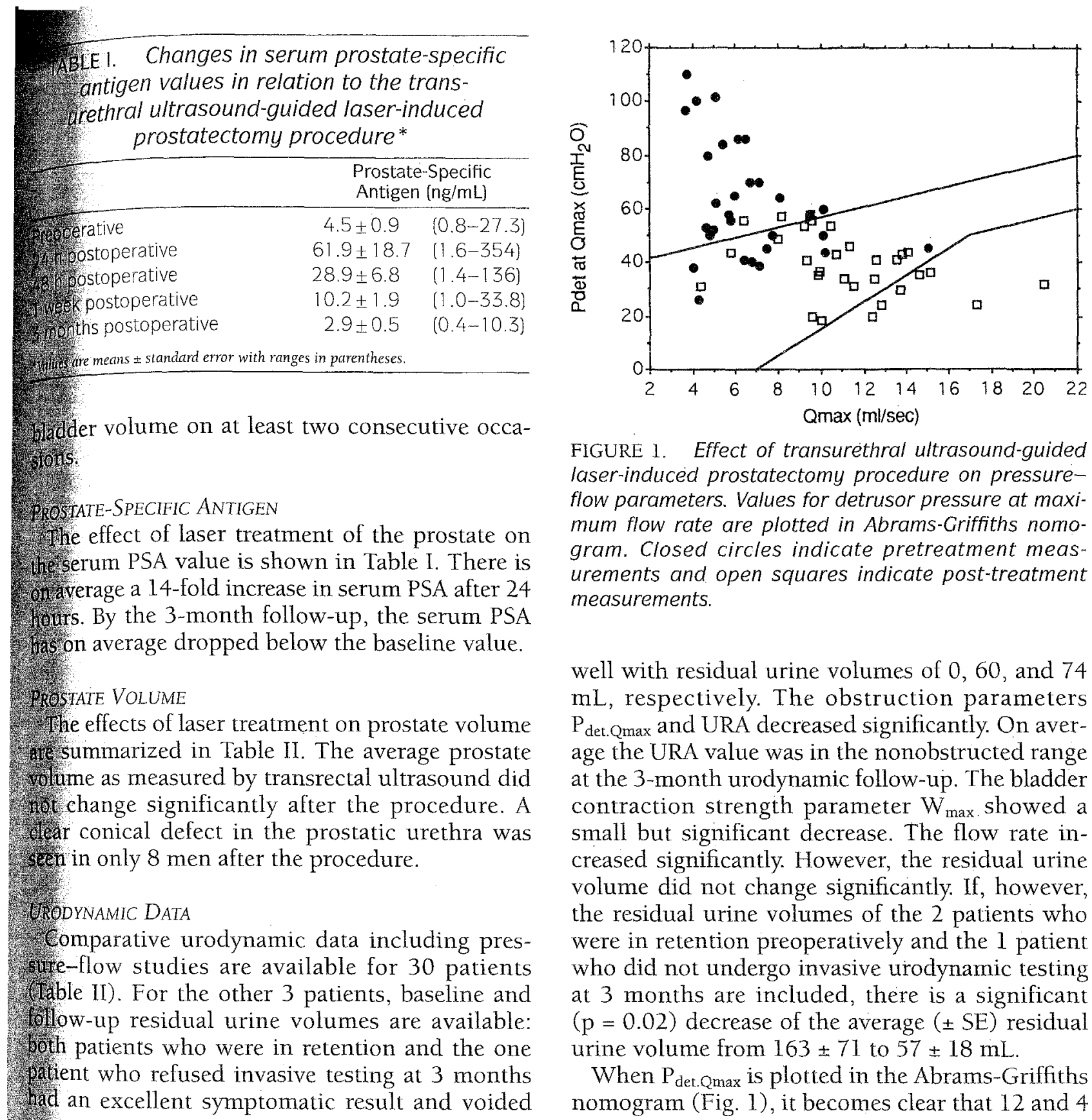

FIGURE 1. Effect of transurethral ultrasound-guided laser-induced prostatectomy procedure on pressureflow parameters. Values for detrusor pressure at maximum flow rate are plotted in Abrams-Griffiths nomogram. Closed circles indicate pretreatment measurements and open squares indicate post-treatment measurements.

well with residual urine volumes of 0,60 , and 74 $\mathrm{mL}$, respectively. The obstruction parameters $P_{\text {det.Qmax }}$ and URA decreased significantly. On average the URA value was in the nonobstructed range at the 3-month urodynamic follow-up. The bladder contraction strength parameter $\mathrm{W}_{\max }$ showed a small but significant decrease. The flow rate increased significantly. However, the residual urine volume did not change significantly. If, however, the residual urine volumes of the 2 patients who were in retention preoperatively and the 1 patient who did not undergo invasive urodynamic testing at 3 months are included, there is a significant $(\mathrm{p}=0.02)$ decrease of the average $( \pm \mathrm{SE})$ residual urine volume from $163 \pm 71$ to $57 \pm 18 \mathrm{~mL}$.

When $P_{\text {det. }}$ max is plotted in the Abrams-Griffiths nomogram (Fig. 1), it becomes clear that 12 and 4 
TABLE III. Effects of transurethral ultrasoundguided laser-induced prostatectomy procedure on individual symptoms and total AUA symptom score at 3 and 6 months follow-up*

\begin{tabular}{lccc}
\hline & & \multicolumn{2}{c}{ Follow-up } \\
\cline { 3 - 4 } Symptoms & Baseline & $\begin{array}{c}3 \text { Months } \\
(\mathrm{n}=26)\end{array}$ & $\begin{array}{c}6 \text { Months } \\
(\mathrm{n}=26)\end{array}$ \\
\hline Emptying & $3.1(0-5)$ & $1.4(0-5)$ & $1.2(0-5)$ \\
Frequency & $3.4(0-5)$ & $2.3(0-5)$ & $1.7(0-5)$ \\
Intermittency & $2.8(0-5)$ & $0.8(0-4)$ & $1.0(0-5)$ \\
Urgency & $2.6(0-5)$ & $2.2(0-5)^{*}$ & $1.5(0-5)$ \\
Weak stream & $4.2(2-5)$ & $1.3(0-5)$ & $1.3(0-5)$ \\
Hesitancy & $1.5(0-5)$ & $0.3(0-2)$ & $0.4(0-4)$ \\
Nocturia & $2.7(1-5)$ & $2.0(0-5)$ & $1.8(0-4)$ \\
AUA-7 index & $20.4(5-35)$ & $10.3(2-23)$ & $8.8(1-26)$
\end{tabular}

*Values are means with ranges in parentheses. All changes in scores are statistically significant $(p<0.05)$ when compared with baseline, except that marked with an asterisk.

patients, respectively, move from the obstructed area to the equivocal area and from the obstructed to the nonobstructive area. Three patients move from the equivocal to the nonobstructed area. Four and 7 patients, respectively, remain in the obstructed and in the equivocal areas. Preoperatively, 20 patients were in the obstructive and 10 in the equivocal range, whereas at the 3-month urodynamic follow-up, 4 men remained in the obstructive area and 19 and 7 were in the equivocal and nonobstructive areas, respectively.

The average $( \pm \mathrm{SE})$ residual urine volumes at 6 and 12 months were $34 \pm 12$ and $35 \pm 12 \mathrm{~mL}$, respectively; these values were not significantly different from the values at the 3-month follow-up.

\section{SYMPTOMS}

Baseline and 3-month symptom score data were available for 32 patients (Table II; 1 patient did not complete a symptom score preoperatively). There was no correlation between the percentage change in urethral resistance (URA) and the percentage change in the total symptom score $(\mathrm{r}=0.13 ; \mathrm{p}=$ 0.537) at the 3-month follow-up.

The baseline, 3- and 6-month follow-up symptom data of the 26 patients who have completed a minimum follow-up of 6 months are summarized in Table III. Laser treatment of the prostate results in a significant improvement of the individual symptoms and the total score on the AUA-7 index. It takes between 3 and 6 months for the symptom "urgency" to improve significantly. This reflects the severe irritative symptoms that are sometimes encountered in the first weeks after the procedure.

In 17 patients the 12-month follow-up has been reached. The total score and the scores for the in- dividual symptoms were not significantly differert? from the 6-months data, except for the symptom "weak stream" which showed an increase from $0: 0$ to $1.6(p=0.03)$.

\section{REPEAT URODYNAMICS AFTER 3 MONTHS AND RETREATMENT}

At 6 months, the symptom index had increased again significantly in 1 patient, but the residua urine volume in this patient was $0 \mathrm{~mL}$ as oppose to $80 \mathrm{~mL}$ preoperatively. At 12 months, a repea urodynamic study was done in 1 patient because of a deteriorating symptom score and an increas ing residual urine volume. The urodynamic stud showed an increased urethral resistance and transurethral resection of the prostate (TURP was subsequently performed in this patient TURP was performed in 1 additional patient the 12-month follow-up. This patient develope macroscopic hematuria due to his benign prosta tic hyperplasia and underwent a TURP in spite o the fact that the AUA symptom score remained low.

\section{COMPLICATIONS}

Few complications were seen. The procedur had to be abandoned in 1 patient, who is not in cluded in this series, because of a false passage of the TULIP probe. Water intoxication did not occu in any of the patients. No blood transfusions wer necessary. In 1 patient a transurethral catheter had to be inserted for bladder irrigation because bleeding blocking the thin suprapubic cathete This catheter was removed again 3 hours later. $O$ patient needed intravenous antibiotics because septicemia. In another patient drug fever developec due to the routinely administered antibiotics. No urethral strictures have been found during follow up. No patient has complained of incontinence.

\section{COMMENT}

There is still a paucity of articles dealing will results of laser treatment of the prostate. Kabalii has compared the results of TURP and VLAP in and 13 patients, respectively, and found compara ble improvements in symptom score and maxi mum flow rate at 3 and 6 months follow-up. A 10 fold increase in serum PSA was noted after lase treatment. In the present series a 14-fold increas was found on average. Norris et al. ${ }^{4}$ reported anat erage increase in flow rate from 7.6 to $12 \mathrm{mll}$ after visual laser ablation of the prostate. $\mathrm{McCl}$ lough et al. ${ }^{2}$ have reported on the results ? 6 months follow-up in 63 patients treated wit the TULIP procedure. In these men the modifie 
sky symptom score ${ }^{12}$ decreased from $18.8 \pm 5$ 14 4.4 and the maximum flow rate increased $6.7 \pm 3.2$ to $11.9 \pm 4.7 \mathrm{~mL} / \mathrm{s}$. These results are rable to the results of the present series.

objective data on changes in urethral resisand pressure-flow parameters in relation to prostatectomy are available in the literature. We present study, the average $( \pm \mathrm{SE}$ ) value of the trineter URA showed a decrease from $38.3 \pm 2.7$ 7. $2.3 \pm 1.3 \mathrm{~cm}$ water, which represents an averthange from the clearly obstructed range Oille unobstructed range. These improvements realso apparent when the preoperative and post- ane arive values for $P_{\text {det.Qmax }}$ are plotted in the W16ms-Griffiths nomogram (Fig. 1). These results Indeate that laser treatment of the prostate is 4have effective from a urodynamic point of view. He. Inagnitude of the average change in the value of he urethral resistance parameter is comparable tollie improvement seen in a group of 29 TURP 2. Whents as reported by Rollema and van Mastrigt, ${ }^{13}$ 17of found an average change from 41 to $16 \mathrm{~cm}$ vacter for the parameter URA.

4. 4h tomatically, there is a clear effect as well. 176everage ( \pm SE) AUA symptom score had de4rexsed from $21.3 \pm 1.4$ to $10.7 \pm 1.0$ at 3 months Thow-up. This change is comparable to the thinge found by Barry et al. ${ }^{7}$ in a group of 27 4LP patients who showed a decrease from 17.6 10. 1 at 4 weeks post-TURP. A further decrease to 68. 6 months follow-up, which is found in the 7resent series, is mainly due to an improvement of Heytuency and urgency, which reflects the late imrrovement of the sometimes severe irritative sympThous in the early postoperative period. Seventeen deatents have been followed for 12 months or 1017ger and the scores for the individual symptoms Nid not change significantly between 6 and 12 moniths except for the score of the symptom "weak tream," which increased from 0.9 to 1.6 on aver16( $(\mathrm{p}=0.03)$.

- Tle results of this series show that a significant Uterease in prostate volume as measured by transWul ultrasound is not necessary to achieve a Werearodynamic and symptomatic improvement. TIe minimal changes in prostate volume may not 6e 6 irately reflect the effect on the prostate because Whe is a 14-fold increase in serum PSA 24 hours Whet the treatment, which indicates that considerWhe tissue damage has taken place. Furthermore, 19. average serum PSA at the 3-month follow-up Ins fallen below the baseline value, which may indiegte that tissue loss has taken place. The TULIP Nocedure is an effective treatment for benign Dostatic hyperplasia. The long-term results have to be awaited. The fact that the score of at least one symptom, that is, "weak stream" shows deterioration at the 12-month follow-up indicates that further studies of the durability of the effect of laser treatment of the prostate are certainly necessary.

J.L.H. Ruud Bosch, M.D. Department of Urology AZR-Dijkzigt, H 1073 Dr. Molewaterplein 40 3015 GD Rotterdam, The Netherlands

\section{REFERENCES}

1. Milam DF, and Smith JA Jr: Lasers in urologic surgery-current status (part 2). AUA Update Series 13: 126-131, 1994.

2. McCullough DL, Roth RA, Babayan RK, Gordon JO, Reese JH, Crawford ED, Fuselier HA, Smith JA, Murchison RJ, and Kaye KW: Transurethral ultrasound-guided laser-induced prostatectomy: National Human Cooperative Study results. J Urol 150: 1607-1611, 1993.

3. Kabalin JN: Laser prostatectomy performed with a right angle firing neodymium:YAG laser fiber at 40 watts power setting. J Urol 150: 95-99, 1993.

4. Norris JP, Norris DM, Lee RD, and Rubenstein MA: Visual laser ablation of the prostate: clinical experience in 108 patients. J Urol 150: 1612-1614, 1993.

5. Roth RA, and Aretz HT: Transurethral ultrasoundguided laser-induced prostatectomy (TULIP procedure): a canine prostate feasibility study. J Urol 146: 1128-1135, 1991

6. Torp-Pedersen S, Juul N, and Jakobsen H: Transrectal prostatic ultrasonography. Equipment, normal findings, benign hyperplasia and cancer. Scand J Urol Nephrol (Suppl) 107: 19-25, 1988.

7. Barry MJ, Fowler FJ Jr, O'Leary MP, Bruskewitz RC, Holtgrewe HL, Mebust WK, and Cockett ATK: The American Urological Association symptom index for benign prostatic hyperplasia. The measurement committee of the American Urological Association. J Urol 148: 1549-1557, 1992.

8. Roehrborn CG, and Peters PC: Can transabdominal ultrasound estimation of postvoiding residual (PVR) replace catheterization? Urology 31: 445-449, 1988.

9. Griffiths $D$, van Mastrigt $R$, and Bosch R: Quantification of urethral resistance and bladder function during voiding, with special reference to the effects of prostate size reduction on urethral obstruction due to benign prostatic hyperplasia. Neurourol Urodyn 8: 17-27, 1989

10. Griffiths DJ, Constantinou $C E$, and van Mastrigt $R$ Urinary bladder function and its control in healthy females. Am J Physiol 251: R225-R230, 1986.

11. Abrams PH, and Griffiths DJ: The assessment of prostatic obstruction from urodynamic measurements and from residual urine. Br J Urol 51: 129-134, 1979.

12. Boyarsky S, Jones G, Pautson DF, and Prout GR Jr: A new look at bladder neck obstruction by the Food and Drug Administration regulators: guide lines for the investigation of benign prostatic hypertrophy. Trans Am Assoc Genitourin Surg 68: 29-32, 1976.

13. Rollema HJ, and van Mastrigt R: Improved indication and followup in transurethral resection of the prostate using the computer program CLIM: a prospective study. J Urol 148: $111-116,1992$ 